\title{
Atrial fibrillation ablation in patients with heart failure review
}

\author{
Mohammad I. Amin ${ }^{1,2 *}$, Laurence D. Sterns ${ }^{1}$, Richard A. Leather ${ }^{1}$, Anthony S. Tang ${ }^{1}$ \\ ${ }^{1}$ Department of Cardiology, Royal Jubilee Hospital, Victoria, Canada \\ ${ }^{2}$ Sh. Mohammed Bin Khalifa Bin Salman Al Khalifa Cardiac Centre, Bahrain Defence Force Hospital, Manama, Kingdom of Bah- \\ rain \\ Email: *drmohdamin@,gmail.com
}

Received 30 November 2012; revised 4 January 2013; accepted 14 January 2013

\begin{abstract}
Atrial fibrillation and heart failure often coexist in patients with advanced heart failure symptoms. The result, in addition to a significant impact on quality of life, is an increase in the risk of a adverse clinical outcomes including stroke, hospitalization and overall mortality. Pharmacological therapy for atrial fibrillation in the heart failure population remains limited due to sub-optimal drug efficacy and a likely increased mortality due to pro-arrhythmia. Atrial fibrillation ablation, since it allows for therapy without the need for toxic medication, has the potential to become mainstream treatment in patients with drug refractory, symptomatic atrial fibrillation and heart failure. Randomized studies and observational data suggest that atrial fibrillation ablation provides superior rhythm control to anti-arrhythmic drugs. Atrial fibrillation ablation is relatively safe and may result in improvement of left ventricular function and quality of life. Ongoing studies are attempting to assess a number of outcome measures to help define its role in the heart failure patient population. This review focuses on atrial fibrillation ablation in patients with congestive heart failure, and summarizes the results of available literature.
\end{abstract}

Keywords: Atrial Fibrillation; Ablation; Heart Failure

\section{INTRODUCTION}

Atrial Fibrillation (AF) and Heart Failure (HF) are major, and often coexisting, public health burdens, which are increasing in prevalence and incidence [1-3] and affect equally patients with impaired and preserved Left Ventricular (LV) function $[4,5]$.

Atrial fibrillation, which affects $1 \%-2 \%$ of the population of the western world [6], is associated with in-

${ }^{*}$ Corresponding author. creased risk of stroke, hospitalization and overall mortality and has a significant impact on quality of life [7-12]. The prevalence of AF increases in patients with more advanced HF symptoms [13]. Heart failure was present in $34 \%$ of $\mathrm{AF}$ patients, and atrial fibrillation in $42 \%$ of HF patients according to The European Heart Surveys $[14,15]$. There is a direct relationship between New York Heart Association (NYHA) functional class and the presence of AF. Atrial fibrillation prevalence increases from 4 to 40 percent as the NYHA functional class increases from I to IV [16-23]. This association of AF and HF exists also in those with isolated diastolic dysfunction with preserved LV function [24].

Different mechanisms could explain the co-existence of atrial fibrillation and heart failure including: 1) rapid ventricular response leading to rate-related cardiomyopathy [24]; 2) reduced cardiac output from loss of atrial transport $[25,26] ; 3)$ heart failure causing increased atrial filling pressure and atrial dilatation promoting atrial fibrillation by ionic remodeling and atrial fibrosis [27]; and 4) atrial stretch-related effects on atrial electrophysiologic properties such as refractoriness and triggered activity [28]. In fact, treatment to relieve chronic stretch has been demonstrated to reverse this remodeling process $[29,30]$.

Treatment to eliminate $\mathrm{AF}$ in patients with impaired LV function improves LV function [31,32]. Several studies addressed the prognostic influence of the presence of AF in HF. Mamas et al., in a systematic review of 53,969 patients [33], showed that AF is associated with worse prognosis in HF patients whether (OR 1.49) or not (OR 2.0) LV function was impaired.

\section{PHARMACOLOGICAL THERAPY FOR ATRIAL FIBRILLATION IN PATIENTS WITH HEART FAILURE}

Pharmacologic therapy of AF in heart failure is challenging in symptomatic patients despite conventional HF therapy. Drug-based AF rhythm control strategy in HF 
patients has failed to show any survival benefit compared with a rate control strategy in randomized studies such as RACE [34] AF-CHF [35] and ANDROMEDA [36]. This may be because of potential pro-arrhythmia with all antiarrhythmic drugs, including amiodarone [37-40]. In addition, in these rate vs. rhythm control studies, which are intention to treat, there is a significant number of rate control patients who achieve sinus rhythm and conversely a significant number of rhythm control patients in whom AF persists. The somewhat similar rhythm outcomes in the two treatment arms, though valid within the intention to treat, undoubtedly affects the veracity of the results if survival in sinus rhythm vs AF is the desired end point.

Data from AFFIRM [41,42], DIAMOND [43] and other studies [44] suggests that patients maintaining sinus rhythm may have better survival, but the benefit may be offset by the adverse effects of anti-arrhythmic drugs. CAFÉ II study supports this further by showing improved LV function and NT-pro BNP in patients assigned to rhythm control [45].

\section{CATHETER ABLATION OF ATRIAL FIBRILLATION IN PATIENTS WITH HEART FAILURE}

Since the initial reports of catheter ablation for AF rhythm control in 1998 [46], there has been substantial progress in the understanding, technique and technology of catheter ablation such that the procedure is becoming mainstream treatment in patients with drug refractory symptomatic AF. Catheter ablation for AF rhythm control has been found to be a relatively safe, effective and costeffective therapy in both clinical trials and in a worldwide survey $[47,48]$ and has superior efficacy compared to anti-arrhythmic drugs $[49,50]$.

The improvement of LV function, following catheter ablation for AF, may be due to restoration of atrial transport, better ventricular filling and enhanced contractility through Starling mechanism. Sinus rhythm also usually results in better rate control.

Extending this therapy to patients with LV systolic dysfunction is appealing, because of the multiple potential effects of $\mathrm{AF}$ on the multiple pathophysiologic mechanisms of HF [51]. However, because of differences in atrial substrate and co-morbidities, ablation in these important patients may be associated with higher risk for recurrent $\mathrm{AF}$ or complications.

Despite encouraging reported results for catheter ablation in patients with HF, ablation is not widely used in this substantial patient population. Even in experienced high-volume centers, HF is present in only a small proportion of patients undergoing ablation [52-54]. In this review we summarize all the data available from recent AF ablation publication enrolling patients with $\mathrm{HF}$

\section{CATHETER ABLATION OF ATRIAL FIBRILLATION IN PATIENTS WITH IMPAIRED LV FUNCTION}

\subsection{Observational Data}

Several studies [55-64] assessed outcome of AF ablation in patients with impaired LV function (Table 1). The maintenance of sinus rhythm free of anti-arrhythmic drugs post ablation ranged from $50 \%$ up to $87 \%$ (Figure 1). The risk of recurrence was higher in this population with more repeat procedures required, although some studies showed no significant difference compared to the control group and concluded that LV systolic dysfunction by itself is not a predictor of outcome after AF ablation. The patients who underwent AF ablation showed significant improvement in LV Ejection Fraction (EF) ranging from $4.6 \%$ increase in ejection fraction, up to normalization of LVEF suggesting the presence of a reverseble atrial fibrillation-induced ventricular cardiomyopathy in many patients with AF and depressed LV function. This was associated with significant improvement in remodeling, exercise capacity, symptoms, and quality of life. This effect was not observed to the same extent in the medically treated group. The improvement was observed regardless of concurrent structural heart disease and adequacy of rate control before ablation. Performing catheter ablation in patients with LV dysfunction was found to be feasible and not associated with higher procedural complications.

Table 1. Summery of observational and randomized studies of AF ablation in patients with heart failure.

\begin{tabular}{|c|c|c|c|c|c|c|c|c|c|}
\hline Author/study & $\begin{array}{c}\text { Publication } \\
\text { year }\end{array}$ & $\begin{array}{l}\text { Patient } \\
\text { number }\end{array}$ & Age (y) & $\begin{array}{l}\text { Cutoff (or } \\
\text { highest) } \\
\text { LVEF (\%) }\end{array}$ & $\begin{array}{c}\text { Mean } \\
\text { LVEF (\%) }\end{array}$ & $\begin{array}{l}\text { Patients with } \\
\text { CAD (\%) }\end{array}$ & $\begin{array}{l}\text { Type of } \\
\text { AF }\end{array}$ & $\begin{array}{l}\text { Follow-up } \\
\text { (months) }\end{array}$ & Outcome \\
\hline \multicolumn{10}{|c|}{ Impaired LV function } \\
\hline \multicolumn{10}{|c|}{ Observational studies } \\
\hline Chen [55] & 2004 & 94 & $57 \pm 8$ & 40 & $36 \pm 8$ & 78 & $\begin{array}{c}\text { Paroxysmal } \\
\text { and persistent }\end{array}$ & $\begin{array}{l}- \\
-\end{array}$ & $\begin{array}{l}\text { Recurrence related to } \\
\text { LVEF, and pulmonary } \\
\text { vein size. } \\
\text { PVI may be a feasible } \\
\text { therapeutic option }\end{array}$ \\
\hline
\end{tabular}




\section{Continued}

\begin{tabular}{|c|c|c|c|c|c|c|c|c|c|}
\hline Hsu [56] & 2004 & 58 & $56 \pm 10$ & 45 & $35 \pm 7$ & 21 & $\begin{array}{l}\text { Paroxysmal } \\
\text { and persistent }\end{array}$ & 12 & $\begin{array}{l}\text { - Significant improvement } \\
\text { in LVEF, symptoms, } \\
\text { exercise capacity, and } \\
\text { QoL. }\end{array}$ \\
\hline Tondo [57] & 2006 & 40 & $57 \pm 10$ & 40 & $33 \pm 2$ & 25 & $\begin{array}{l}\text { Paroxysmal } \\
\text { and persistent }\end{array}$ & 14 & $\begin{array}{l}\text { - Ablation is feasible, not } \\
\text { associated with higher } \\
\text { procedural complications, } \\
\text { - } \quad \text { Significant improvement } \\
\text { in LVEF, symptoms, and } \\
\text { QoL. }\end{array}$ \\
\hline Gentlesk [58] & 2007 & 67 & $54 \pm 9$ & 50 & $42 \pm 9$ & 18 & $\begin{array}{l}\text { Paroxysmal } \\
\text { and persistent }\end{array}$ & 6 & $\begin{array}{l}\text { Maintenance of SR associated } \\
\text { with more LVEF improvement }\end{array}$ \\
\hline Efremidis [59] & 2007 & 13 & $54 \pm 12$ & 40 & $36 \pm 5$ & 23 & $\begin{array}{l}\text { Paroxysmal } \\
\text { and persistent }\end{array}$ & 9 & $\begin{array}{l}\text { AF ablation is effective } \\
\text { method of maintaining } \\
\text { sinus rhythm } \\
\text { - Improvement in LVEF, } \\
\text { and reversing atrial and } \\
\text { ventricular remodelling }\end{array}$ \\
\hline Nademanee [60] & 2008 & 129 & $67 \pm 12$ & 40 & $31 \pm 7$ & 21 & $\begin{array}{l}\text { Paroxysmal } \\
\text { and persistent }\end{array}$ & 27 & $\begin{array}{ll}\text { - } & \text { Duration of AF, LA size > } \\
50 \mathrm{~mm} \text { are associated with } \\
\text { recurrence } \\
\text { - } \\
\begin{array}{l}\text { Maintenance of SR } \\
\text { predicts survival }\end{array}\end{array}$ \\
\hline Lutomsky [61] & 2008 & 18 & $56 \pm 11$ & 50 & $41 \pm 6$ & 17 & Paroxysmal & 6 & $\begin{array}{l}\text { Pulmonary vein isolation } \\
\text { improves cardiac function }\end{array}$ \\
\hline De Potter [62] & 2010 & 36 & $49 \pm 10$ & 50 & $43 \pm 7$ & 19 & $\begin{array}{l}\text { Paroxysmal } \\
\text { and persistent }\end{array}$ & 6 & $\begin{array}{l}\text { - LA size, not LVEF or AF } \\
\text { duration, predicts } \\
\text { recurrence } \\
\text { - } \\
\text { Similar improvement in } \\
\text { LVEF in both ischemic } \\
\text { and nonischemic }\end{array}$ \\
\hline Choi [63] & 2010 & 15 & $56 \pm 11$ & 45 & $37 \pm 6$ & 33 & $\begin{array}{l}\text { Paroxysmal } \\
\text { and persistent }\end{array}$ & 16 & $\begin{array}{l}\text { PVI significantly improved } \\
\text { LVEF and NYHA class }\end{array}$ \\
\hline Cha [64] & 2011 & 111 & $55 \pm 6$ & 40 & $35 \pm 5$ & 13 & $\begin{array}{l}\text { Paroxysmal } \\
\text { and persistent }\end{array}$ & 13 & $\begin{array}{l}\text { Increased risk of arrhythmia } \\
\text { recurrence compared with } \\
\text { normal function. }\end{array}$ \\
\hline \multicolumn{10}{|c|}{ Randomized studies } \\
\hline $\begin{array}{c}\text { Khan } \\
\text { (PABACHF) [65] }\end{array}$ & 2008 & 41 & $60 \pm 8$ & 40 & $27 \pm 8$ & 73 & $\begin{array}{l}\text { Paroxysmal } \\
\text { and persistent }\end{array}$ & 6 & $\begin{array}{l}\text { PVI superior to } \\
\text { atrioventricular-node ablation } \\
\text { with biventricular pacing in } \\
\text { patients with heart failure }\end{array}$ \\
\hline MacDonald [66] & 2011 & 22 & $62 \pm 7$ & 35 & $36 \pm 12$ & 50 & Persistent & 10 & 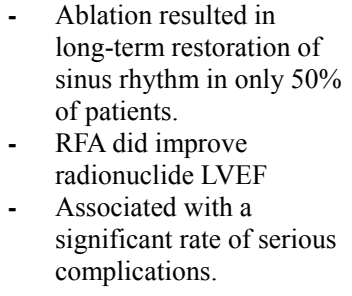 \\
\hline \multicolumn{10}{|c|}{ Preserved LV function } \\
\hline Cha [64] & 2011 & 157 & $62 \pm 2$ & $\geq 50$ & $62 \pm 2$ & 17 & $\begin{array}{l}\text { Paroxysmal } \\
\text { and persistent }\end{array}$ & 13 & $\begin{array}{l}\text { Ablation associated with im- } \\
\text { provement in QoL and LV } \\
\text { functional benefit. }\end{array}$ \\
\hline
\end{tabular}




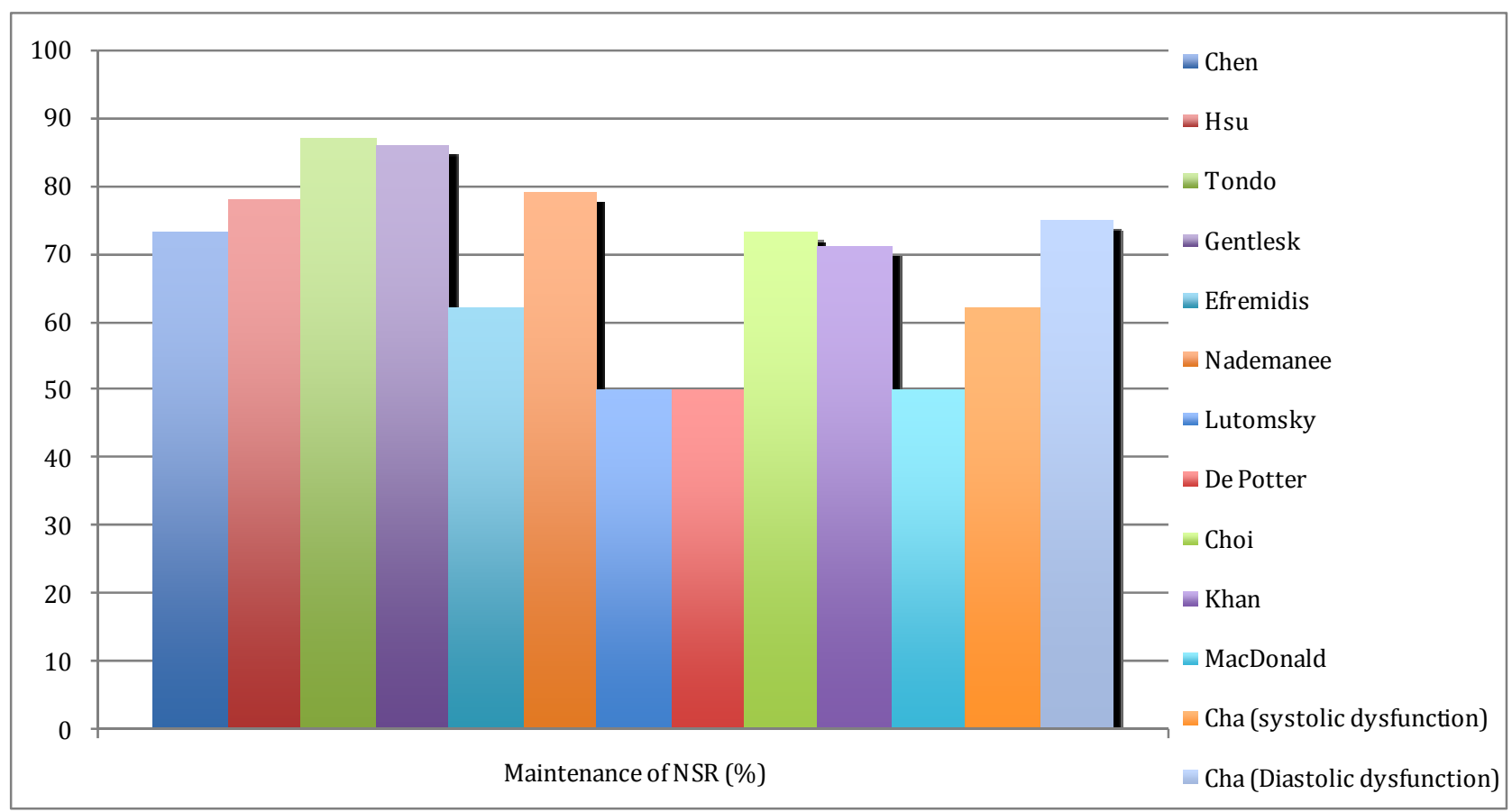

Figure 1. Rate of maintenance of NSR without AADs post AF ablation in patients with heart failure.

\subsection{Randomised Controlled Trials}

Khan et al. [65] randomized 81 patients with symptomatic drug-resistant AF, an EF of $40 \%$ or less, and NYHA class II or III heart failure to either pulmonary vein isolation or atrio-ventricular nodal ablation with biventricular pacing. Out of 41 patients in the pulmonary vein isolation arm, $71 \%$ were free of AF without anti-arrhythmic drugs at 6 months follow-up. Catheter ablation for $\mathrm{AF} / \mathrm{HF}$ patients with impaired LV resulted in improvements in LVEF (35\% vs $28 \%, \mathrm{P}<0.001)$, quality of life ( 60 vs 82 on questionnaire score, $\mathrm{P}<0.001)$ and 6-minute walk distance (340 m vs $297 \mathrm{~m}, \mathrm{P}<0.001$ ) compared to patients treated with rate control by $\mathrm{AV}$ nodal ablation and biventricular pacing.

MacDonald et al. [66] randomised 41 patients with persistent AF, advanced $\mathrm{HF}$ and severe LV dysfunction to AF ablation (rhythm control) or continued medical treatment (rate control). Patients were followed up for a minimum of 6 months. In the ablation group, $50 \%$ of patients were in sinus rhythm at the end of the study. The ablation group had a greater increase in LVEF (using either cardiovascular magnetic resonance or radionuclide determinations) than patients in the medical treatment group although this did not reach statistical significance. AF ablation did not improve N-terminal pro-BNP, 6 min walk distance or quality of life. The rate of serious complications related to ablation was 15\% (1 stroke, 2 tamponade recovered after emergency pericardiocentesis without long-term complications, 3 worsening heart failure requiring adjustment of diuretic therapy/hospitalization).
There are several limitations to this study including small sample size with lower than predicted success rate and baseline imbalances between the treatment groups. As well, this was a single centre study with a single operator performing the ablation procedures.

\subsection{Metanalysis}

Wilton et al. [67] performed a systematic review and metaanalysis of 7 randomized and observational studies including 1851 patients, comparing the rates of recurrent AF, atrial tachycardia and complications after AF catheter ablation in patients with normal compared to impaired LV systolic function. Sixty-four percent to $96 \%$ of patients with LV dysfunction were free of AF or atrial tachycardia after a mean of 1.4 procedures. There were no differences in complication rates. After catheter ablation, patients with systolic LV dysfunction experienced a pooled absolute improvement in the LVEF of $11 \%$.

Dagres et al. [68] performed meta-analysis on 9studies involving 354 patients with LV dysfunction to assess change in LVEF after catheter ablation of AF. A similar $11.1 \%$ LVEF improvement post ablation was reported. The presence of coronary artery disease predicted failure of LVEF improvement. There was no association between LVEF change and AF recurrence during follow-up.

\section{CATHETER ABLATION OF ATRIAL FIBRILLATION IN PATIENTS WITH PRESEVED LV FUNCTION}

Cha et al. [64] assessed catheter ablation for anti-arrhy- 
thmic drug-refractory AF in 368 patients with HF. They compared 3 groups prospectively: $111 \mathrm{HF}$ patients with systolic dysfunction, defined as LVEF $\leq 40 \% ; 157 \mathrm{HF}$ patients with isolated diastolic dysfunction but preserved LVEF $\geq 50 \%$; and 100 control patients without HF and with normal LV function. The primary end point was freedom from $\mathrm{AF}$ and anti-arrhythmic drugs at one year post ablation. This end point was achieved in $62 \%$ of patients with systolic dysfunction, $75 \%$ of those with diastolic dysfunction, and $84 \%$ of controls $(\mathrm{P}=0.007)$. AF control on or off drug was achieved in $76 \%$ of patients with systolic dysfunction, $85 \%$ of those with diastolic dysfunction, and $89 \%$ of controls $(\mathrm{P}=0.08)$. In the systolic dysfunction group, $49 \%$ experienced an increase in LVEF by $\geq 5 \%$ after ablation. Of these, $64 \%$ achieved normalization of LVEF. In the diastolic dysfunction group, $30 \%$ of patients demonstrated at least one grade improvement in diastolic dysfunction. They concluded that an ablation approach for AF has the potential for substantial quality-of-life improvement and LV functional benefit.

\section{ONGOING STUDIES}

To date, published, randomized trials involve only small numbers of patients but suggest benefit of catheter ablation for rhythm control for atrial fibrillation patients with heart failure whether or not LV function is preserved. Larger scale, randomized studies assessing a number of endpoints, including hard endpoints, are needed and indeed there are multiple ongoing studies looking into outcomes, predictors of success, and safety in this high risk population.

Pulmonary Vein Isolation for Rhythm Control in Patients with Atrial Fibrillation and Left Ventricular Dysfunction (Catheter Ablation for AF \& HF) [69] is an observational study enrolling patients with NYHA IIII CHF on optimal medical therapy with planned catheter ablation for paroxysmal or persistent AF. Primary endpoint is improvement in LV end systolic volume by $15 \%$ or more frombaseline at 6 months. Secondary endpoints include remodeling as demonstrated by atrial and ventricular dimensions on echocardiography, NYHA class, quality of life and six minute hall walk test. Composites of hospitalization for heart failure, thrombo-embolism, major bleeding or all cause mortality, as well as absence of AF will also be assessed. This study was withdrawn prior to enrollment.

Catheter Ablation Versus Medical Treatment of AF in Heart Failure (CAMTAF) [70] is an open label, parallel assignment study randomizing patients with $\mathrm{HF}$ and persistent AF to medical treatment or catheter ablation to restore sinus rhythm. The primary end point is the difference in LVEF between groups. Secondary outcomes include differences in peak $\mathrm{VO}_{2}$, NYHA class, BNP, quality of life, reduction in end systolic volume, and difference in HF symptoms. The study is complete but not yet published.

Catheter Ablation Versus Medical Rate Control for Atrial Fibrillation in Patients with Heart Failure (ARC-HF) [71] is a prospective study enrolling HF patients on optimal therapy, with documented persistent AF, and comparing the strategies of catheter-ablation and medical rate control in a 1:1 randomized fashion. The primary end point is difference in peak oxygen consumption at cardiopulmonary exercise test. Secondary endpoints includes changes in LVEF, quality of life score, 6 minutes walk test, BNP levels, and freedom from AF. The study is complete but not yet published

AMICA Atrial Fibrillation Management in Congestive Heart Failure with Ablation [72] is a randomized, open label study in symptomatic AF patients comparing the effect of AF ablation plus ICD/CRT implant to best medical treatment plus ICD/CRT implant in patients with reduced $\mathrm{EF}$ of less than $35 \%$ who are felt to require ICD or CRT-D implantation. Primary endpoint is LVEF improvement as determined by echocardiography. This study is estimated to complete in 2013.

CASTLE-AF Catheter Ablation Versus Standard Conventional Treatment in Patients with Left Ventricular Dysfunction and Atrial Fibrillation [73] is a prospective, open label, randomized, multicenter study comparing the effect of catheter ablation to conventional treatment in HF patients with AF. Eligible patients are those with LV dysfunction (LVEF $\leq 35 \%$ ) and NYHA class $\geq$ II who have already been implanted with a dual chamber ICD with Home Monitoring ${ }^{\circledR}$ capabilities. The primary endpoint is the composite of all-cause mortality or worsening of heart failure requiring unplanned hospitalization using a time to first event analysis. Secondary endpoints are all-cause mortality, cardiovascular mortality, cerebrovascular accidents, worsening of HF requiring unplanned hospitalization, unplanned hospitalization due to cardiovascular reason, all-cause hospitalization, quality of life, number of therapies (shock and anti-tachycardia pacing) delivered by the ICD, time to first ICD therapy, number of device-detected ventricular tachycardia and ventricular fibrillation episodes, AF burden, AFfree interval, LVEF, exercise tolerance, and percentage of right ventricular pacing. This study should be completed in 2015 .

Rate Versus Catheter Ablation Rhythm Control in Patients With Heart Failure and High Burden Atrial Fibrillation (RAFT-AF) [74] is a large multicentre, randomized, open label study comparing catheter ablation for $\mathrm{AF}$ rhythm control to rate control in patients with $\mathrm{HF}$ (NYHA II-III, on optimal medical therapy, and elevated NT-pro BNP) and high burden AF. Primary end point will be cardiovascular mortality. Cost-effectiveness and 
quality of life will be secondary end points. The study is currently recruiting, and anticipated completion is 2016.

\section{CONCLUSIONS}

$\mathrm{AF}$ and $\mathrm{HF}$ with impaired or preserved LV function coexist with increasing prevalence. $\mathrm{AF}$ in such patients is associated with increased mortality as well as deterioration of LV function, NYHA class, exercise tolerance, and quality of life. Pharmacological therapy of AF in this population is limited due somewhat to suboptimal efficacy and increased risk of pro-arrhythmia.

Observational data suggests $\mathrm{AF}$ ablation is a superior modality for rhythm control with significant improvement in LVEF, symptomatic state, and quality of life. This is further supported by data from small size randomized studies showing feasibility and safety of AF ablation with improved outcome in patients with HF.

Ongoing studies will hopefully shed light on a multitude of endpoints, particularly hard endpoints such as mortality and hospitalizations and further characterize the optimal heart failure patient subgroups.

\section{REFERENCES}

[1] Braunwald, E. (1997) Shattuck lecture-cardiovascular medicine at the turn of the millennium: Triumphs, concerns, and opportunities. The New England Journal of Medicine, 337, 1360-1369. doi:10.1056/NEJM199711063371906

[2] Lloyd-Jones, D., et al. (2010) Heart disease and stroke statistics - 2010 update: A report from the American Heart Association. Circulation, 121, e46-e215. doi:10.1161/CIRCULATIONAHA.109.192667

[3] Johansen, H., et al. (2003) On the rise: The current and projected future burden of congestive heart failure hospitalization in Canada. Canadian Journal of Cardiology, 19, 430-435.

[4] Bursi, F., et al. (2006) Systolic and diastolic heart failure in the community. JAMA, 296, 2209-2216. doi:10.1001/jama.296.18.2209

[5] Owan, T.E., et al. (2006) Trends in prevalence and outcome of heart failure with preserved ejection fraction. The New England Journal of Medicine, 355, 251-259. doi:10.1056/NEJMoa052256

[6] Klein, L., et al. (2003) Pharmacologic therapy for patients with chronic heart failure and reduced systolic function: Review of trials and practical considerations. American Journal of Cardiology, 91, 18F-40F. doi:10.1016/S0002-9149(02)03336-2

[7] Benjamin, E.J., et al. (1998) Impact of atrial fibrillation on the risk of death: The Framingham heart study. Circulation, 98, 946-952. doi:10.1161/01.CIR.98.10.946

[8] Vidaillet, H., et al. (2002) A population-based study of mortality among patients with atrial fibrillation or flutter. American Journal of Medicine, 113, 365-370. doi:10.1016/S0002-9343(02)01253-6
[9] Haywood, L.J., et al. (2009) Atrial fibrillation at baseline and during follow-up in ALLHAT (Antihypertensive and Lipid-Lowering Treatment to Prevent Heart Attack Trial). Journal of the American College of Cardiology, 54, 20232031. doi:10.1016/j.jacc.2009.08.020

[10] Wattigney, W.A., Mensah, G.A. and Croft, J.B. (2003) Increasing trends in hospitalization for atrial fibrillation in the United States, 1985 through 1999: Implications for primary prevention. Circulation, 108, 711-716. doi:10.1161/01.CIR.0000083722.42033.0A

[11] Dorian, P., et al. (2000) The impairment of health-related quality of life in patients with intermittent atrial fibrillation: Implications for the assessment of investigational therapy. Journal of the American College of Cardiology, 36, 1303-1309. doi:10.1016/S0735-1097(00)00886-X

[12] Singh, S.N., et al. (2006) Quality of life and exercise performance in patients in sinus rhythm versus persistent atrial fibrillation: A veterans affairs cooperative studies program substudy. Journal of the American College of Cardiology, 48, 721-730. doi:10.1016/j.jacc.2006.03.051

[13] Ehrlich, J.R., Nattel, S. and Hohnloser, S.H. (2002) Atrial fibrillation and congestive heart failure: Specific considerations at the intersection of two common and important cardiac disease sets. Journal of Cardiovascular Electrophysiology, 13, 399-405. doi:10.1046/j.1540-8167.2002.00399.x

[14] Cleland, J.G., et al. (2003) The EuroHeart Failure survey programme - A survey on the quality of care among patients with heart failure in Europe. Part 1: Patient characteristics and diagnosis. European Heart Journal, 24, 442463. doi:10.1016/S0195-668X(02)00823-0

[15] Nieuwlaat, R., et al. (2005) Atrial fibrillation management: A prospective survey in ESC member countries: The Euro Heart survey on atrial fibrillation. European Heart Journal, 26, 2422-2434. doi:10.1093/eurheartj/ehi505

[16] Cohn, J.N., Johnson, G., Ziesches, S., et al. (1991) A comparison of enalapril with hydralazine-isosorbide dinitrate in the treatment of chronic congestive heart failure. The New England Journal of Medicine, 325, 303-310. doi:10.1056/NEJM199108013250502

[17] Cohn, J.N., Archibald, D.G., Ziesche, S., Franciosa, J.A., Harston, W.E., Tristani, F.E., Dunkman, W.B., Jacobs, W., Francis, G.S. and Flohr, K.H. (1986) Effect of vasodilator therapy on mortality in chronic congestive heart failure. Results of a veterans administration cooperative study. The New England Journal of Medicine, 314, 15471552. doi:10.1056/NEJM198606123142404

[18] Doval, H.C., Nul, D.R., Grancelli, H.O., Perrone, S.V., Bortman, G.R. and Curiel, R. (1994) Randomised trial of low-dose amiodarone in severe congestive heart failure. Grupo de Estudio de la Sobrevida en la Insuficiencia Cardiaca en Argentina (GESICA). The Lancet, 344, 493-498. doi:10.1016/S0140-6736(94)91895-3

[19] Johnstone, D., Limacher, M., Rousseau, M., Liang, C.S., Ekelund, L., Herman, M., Stewart, D., Guillotte, M., Bjerken, G. and Gaasch, W. (1992) Clinical characteristics of patients in studies of left ventricular dysfunction (SOLVD). American Journal of Cardiology, 70, 894-900. 
doi:10.1016/0002-9149(92)90734-G

[20] Packer, M., Poole-Wilson, P.A., Armstrong, P.W., Cleland, J.G., Horowitz, J.D., Massie, B.M., Rydén, L., Thygesen, K., Uretsky, B.F. and ATLAS Study Group (1999) Comparative effects of low and high doses of the angiotensin-converting enzyme inhibitor, lisinopril, on morbidity and mortality in chronic heart failure. Circulation, 100, 2312-2318. doi:10.1161/01.CIR.100.23.2312

[21] Singh, S.N., Fletcher, R.D., Fisher, S.G., Singh, B.N., Lewis, H.D., Deedwania, P.C., Massie, B.M., Colling, C. and Lazzeri, D. (1995) Amiodarone in patients with congestive heart failure and asymptomatic ventricular arrhythmia. Survival trial of antiarrhythmic therapy in congestive heart failure. The New England Journal of Medicine, 333, 77-82. doi:10.1056/NEJM199507133330201

[22] The CONSENSUS Trial Study Group (1987) Effects of enalapril on mortality in severe congestive heart failure. Results of the cooperative north Scandinavian enalapril survival study (CONSENSUS). The New England Journal of Medicine, 316, 1429-1435. doi:10.1056/NEJM198706043162301

[23] Yusuf, S., Pepine, C.J., Garces, C., Pouleur, H., Salem, D., Kostis, J., Benedict, C., Rousseau, M., Bourassa, M. and Pitt, B. (1992) Effect of enalapril on myocardial infarction and unstable angina in patients with low ejection fractions. The Lancet, 340, 1173-1178. doi:10.1016/0140-6736(92)92889-N

[24] Tsang, T.S., Gersh, B.J., Appleton, C.P., Tajik, A.J., Barnes, M.E., Bailey, K.R., Oh, J.K., Leibson C, Montgomery, S.C. and Seward, J.B. (2002) Left ventricular diastolic dysfunction as a predictor of the first diagnosed nonvalvular atrial fibrillation in 840 elderly men and women. Journal of the American College of Cardiology, 40, 1636-1644. doi:10.1016/S0735-1097(02)02373-2

[25] Shinbane, J.S., et al. (1997) Tachycardia-induced cardiomyopathy: A review of animal models and clinical studies. Journal of the American College of Cardiology, 29, 709-15. doi:10.1016/S0735-1097(96)00592-X

[26] Pozzoli, M., et al. (1998) Predictors of primary atrial fibrillation and concomitant clinical and hemodynamic changes in patients with chronic heart failure: A prospective study in 344 patients with baseline sinus rhythm. Journal of the American College of Cardiology, 32, 197204. doi:10.1016/S0735-1097(98)00221-6

[27] Li, D., et al. (1999) Promotion of atrial fibrillation by heart failure in dogs: Atrial remodeling of a different sort. Circulation, 100, 87-95. doi:10.1161/01.CIR.100.1.87

[28] Sanders, P., et al. (2003) Electrical remodeling of the atria in congestive heart failure: Electrophysiological and electroanatomic mapping in humans. Circulation, 108, 1461-1468. doi:10.1161/01.CIR.0000090688.49283.67

[29] Sparks, P.B., et al. (1999) Electrical remodeling of the atria following loss of atrioventricular synchrony: A longterm study in humans. Circulation, 100, 1894-1900. doi:10.1161/01.CIR.100.18.1894

[30] John, B., et al. (2010) Reverse remodeling of the atria after treatment of chronic stretch in humans: Implications for the atrial fibrillation substrate. Journal of the American College of Cardiology, 55, 1217-1226. doi:10.1016/j.jacc.2009.10.046

[31] Sanders, P., et al. (2003) Reversal of atrial mechanical dysfunction after cardioversion of atrial fibrillation: Implications for the mechanisms of tachycardia-mediated atrial cardiomyopathy. Circulation, 108, 1976-1984. doi:10.1161/01.CIR.0000091408.45747.04

[32] Wilton, S.B. (2010) Investigation of non-pharmacological therapies in patients with heart failure and atrial fibrillation, University of Calgary, Calgary.

[33] Mamas, M.A., et al. (2009) A meta-analysis of the prognostic significance of atrial fibrillation in chronic heart failure. European Journal of Heart Failure, 11, 676-683. doi:10.1093/eurjhf/hfp085

[34] Hagens, V.E., et al. (2005) Rate control versus rhythm control for patients with persistent atrial fibrillation with mild to moderate heart failure: Results from the RAte control versus electrical cardioversion (RACE) study. American Heart Journal, 149, 1106-1111. doi:10.1016/j.ahj.2004.11.030

[35] Roy, D., et al. (2008) Rhythm control versus rate control for atrial fibrillation and heart failure. The New England Journal of Medicine, 358, 2667-2677. doi:10.1056/NEJMoa0708789

[36] Kober, L., Torp-Pedersen, C., McMurray, J.J., et al. (2008) Increased mortality after dronedarone therapy for severe heart failure. The New England Journal of Medicine, 358, 2678-2687. doi:10.1056/NEJMoa0800456

[37] Bardy, G.H., et al. (2005) Amiodarone or an implantable cardioverter-defibrillator for congestive heart failure. The New England Journal of Medicine, 352, 225-237. doi:10.1056/NEJMoa043399

[38] Flaker, G.C., et al. (1992) Antiarrhythmic drug therapy and cardiac mortality in atrial fibrillation. The stroke prevention in atrial fibrillation investigators. Journal of the American College of Cardiology, 20, 527-532. doi:10.1016/0735-1097(92)90003-6

[39] Kaufman, E.S., et al. (2004) Risk of proarrhythmic events in the atrial fibrillation follow-up investigation of rhythm management (AFFIRM) study: A multivariate analysis. Journal of the American College of Cardiology, 44, 12761282.

[40] Torp-Pedersen, C., et al. (2007) The safety of amiodarone in patients with heart failure. Journal of Cardiac Failure, 13, 340-345. doi:10.1016/j.cardfail.2007.02.009

[41] Wyse, D.G., et al. (2002) A comparison of rate control and rhythm control in patients with atrial fibrillation. The New England Journal of Medicine, 347, 1825-1833. doi:10.1056/NEJMoa021328

[42] Corley, S.D., et al. (2004) Relationships between sinus rhythm, treatment, and survival in the atrial fibrillation follow-up investigation of rhythm management (AFFIRM) study. Circulation, 109, 1509-1513. doi:10.1161/01.CIR.0000121736.16643.11

[43] Pedersen, O.D., et al. (2001) Efficacy of dofetilide in the treatment of atrial fibrillation-flutter in patients with reduced left ventricular function: A Danish investigations of arrhythmia and mortality on dofetilide (diamond) substudy. Circulation, 104, 292-296. 
doi:10.1161/01.CIR.104.3.292

[44] Deedwania, P.C., Singh, B.N., Ellenbogen, K., Fisher, S., Fletcher, R. and Singh, S.N. (1998) Spontaneous conversion and maintenance of sinus rhythm by amiodarone in patients with heart failure and atrial fibrillation: $\mathrm{Ob}-$ servations from the veterans affairs congestive heart failure survival trial of antiarrhythmic therapy (CHF-STAT). Circulation, 98, 2574-2579. doi:10.1161/01.CIR.98.23.2574

[45] Shelton, R.J., et al. (2009) A randomised, controlled study of rate versus rhythm control in patients with chronic atrial fibrillation and heart failure: (CAFE-II study). Heart, 95, 924-930. doi:10.1136/hrt.2008.158931

[46] Haissaguerre, M., et al. (1998) Spontaneous initiation of atrial fibrillation by ectopic beats originating in the pulmonary veins. The New England Journal of Medicine, 339, 659-666. doi:10.1056/NEJM199809033391003

[47] McKenna, C., et al. (2009) Cost-effectiveness of radiofrequency catheter ablation for the treatment of atrial fibrillation in the United Kingdom. Heart, 95, 542-549. doi:10.1136/hrt.2008.147165

[48] Cappato, R., et al. (2010) Updated worldwide survey on the methods, efficacy, and safety of catheter ablation for human atrial fibrillation. Circulation: Arrhythmia and Electrophysiology, 3, 32-38. doi:10.1161/CIRCEP.109.859116

[49] Nair, G.M., Nery, P.B., Diwakaramenon, S., Healey, J.S., Connolly, S.J. and Morillo, C.A. (2009) A systematic review of randomized trials comparing radiofrequency ablation with antiarrhythmic medications in patients with atrial fibrillation. Journal of Cardiovascular Electrophysiology, 20, 138-144. doi:10.1111/j.1540-8167.2008.01285.x

[50] Wilber, D.J., Pappone, C., Neuzil, P., De Paola, A., Marchlinski, F., Natale, A., Macle, L., Daoud, E.G., Calkins, H., Hall, B., Reddy, V., Augello, G., Reynolds, M.R., Vinekar, C., Liu, C.Y., Berry, S.M., Berry, D.A. and ThermoCool AF Trial Investigators (2010) Comparison of antiarrhythmic drug therapy and radiofrequency catheter ablation in patients with paroxysmal atrial fibrillation: A randomized controlled trial. JAMA, 303, 333-340. doi:10.1001/jama.2009.2029

[51] Anter, E., Jessup, M. and Callans, D.J. (2009) Atrial fibrillation and heart failure: Treatment considerations for a dual epidemic. Circulation, 119, 2516-2525. doi:10.1161/CIRCULATIONAHA.108.821306

[52] Themistoclakis, S., Corrado, A., Marchlinski, F.E., Jais, P., Zado, E., Rossillo, A., et al. (2010) The risk of thromboembolism and need for oral anticoagulation after successful atrial fibrillation ablation. Journal of the American College of Cardiology, 55, 735-743. doi:10.1016/j.jacc.2009.11.039

[53] Dagres, N., Hindricks, G., Kottkamp, H., Sommer, P., Gaspar, T., Bode, K., et al. (2009) Complications of atrial fibrillation ablation in a high-volume center in 1000 procedures: Still cause for concern? Journal of Cardiovascular Electrophysiology, 20, 1014-1019. doi:10.1111/j.1540-8167.2009.01493.x

[54] Tilz, R.R., Chun, K.R., Schmidt, B., Fuernkranz, A.,
Wissner, E., Koester, I., et al. (2010) Catheter ablation of long-standing persistent atrial fibrillation: A lesson from circumferential pulmonary vein isolation. Journal of Cardiovascular Electrophysiology, 21, 1085-1093. doi:10.1111/j.1540-8167.2010.01799.x

[55] Chen, M.S., Marrouche, N.F., Khaykin, Y., Gillinov, A.M., Wazni, O., Martin, D.O., et al. (2004) Pulmonary vein isolation for the treatment of atrial fibrillation in patients with impaired systolic function. Journal of the American College of Cardiology, 43, 1004-1009. doi:10.1016/j.jacc.2003.09.056

[56] Hsu, L.F., Ja€1s, P., Sanders, P., Garrigue, S., Hocini, M., Sacher, F., et al. (2004) Catheter ablation for atrial fibrillation in congestive heart failure. The New England Journal of Medicine, 351, 2373-2378. doi:10.1056/NEJMoa041018

[57] Tondo, C., Mantica, M., Russo, G., Avella, A., De Luca, L., Pappalardo, A., Fagundes, R.L., Picchio, E., Laurenzi, F., Piazza, V. and Bisceglia, I. (2006) Pulmonary vein vestibule ablation for the control of atrial fibrillation in patients with impaired left ventricular function. Pacing and Clinical Electrophysiology, 29, 962-970. doi:10.1111/j.1540-8159.2006.00471.x

[58] Gentlesk, P.J., Sauer, W.H., Gerstenfeld, E.P., Lin, D., Dixit, S., Zado, E., et al. (2007) Reversal of left ventricular dysfunction following ablation of atrial fibrillation. Journal of Cardiovascular Electrophysiology, 18, 9-14. doi:10.1111/j.1540-8167.2006.00653.x

[59] Efremidis, M., Sideris, A., Xydonas, S., Letsas, K.P., Alexanian, I.P., Manolatos, D., et al. (2008) Ablation of atrial fibrillation in patients with heart failure: Reversal of atrial and ventricular remodelling. The Hellenic Journal of Cardiology, 49, 19-25.

[60] Nademanee, K., Schwab, M.C., Kosar, E.M., Karwecki, M., Moran, M.D., Visessook, N., Michael, A.D. and Ngarmukos, T. (2008) Clinical outcomes of catheter substrate ablation for high-risk patients with atrial fibrillation. Journal of the American College of Cardiology, 51, 843849. doi:10.1016/j.jacc.2007.10.044

[61] Lutomsky, B.A., Rostock, T., Koops, A., Steven, D., M€ullerleile, K., Servatius, H., et al. (2008) Catheter ablation of paroxysmal atrial fibrillation improves cardiac function: a prospective study on the impact of atrial fibrillation ablation on left ventricular function assessed by magnetic resonance imaging. Europace, 10, 593-599. doi:10.1093/europace/eun076

[62] De Potter, T., Berruezo, A., Mont, L., Matiello, M., Tamborero, D., Santibanez, C., et al. (2010) Left ventricular systolic dysfunction by itself does not influence outcome of atrial fibrillation ablation. Europace, 12, 24 29. doi:10.1093/europace/eup309

[63] Choi, A.D., Hematpour, K., Kukin, M., Mittal, S. and Steinberg, J.S. (2010) Ablation vs medical therapy in the setting of symptomatic atrial fibrillation and left ventricular dysfunction. Congestive Heart Failure, 16, 10-14. doi:10.1111/j.1751-7133.2009.00116.x

[64] Cha, Y.M., Wokhlu, A., Asirvatham, S.J., Shen, W.K., Friedman, P.A., Munger, T.M., Oh, J.K., Monahan, K.H., Haroldson, J.M., Hodge, D.O., Herges, R.M., Hammill, 
S.C. and Packer, D.L. (2011) Success of ablation for atrial fibrillation in isolated left ventricular diastolic dysfunction: A comparison to systolic dysfunction and normal ventricular function. Circulation: Arrhythmia and Electrophysiology, 4, 742-32.

[65] Khan, M.N., Jaïs, P., Cummings, J., Di Biase, L., Sanders, P., Martin, D.O., et al. (2008) Pulmonary-vein isolation for atrial fibrillation in patients with heart failure. The New England Journal of Medicine, 359, 1778-1785. doi:10.1056/NEJMoa0708234

[66] MacDonald, M.R., Connelly, D.T., Hawkins, N.M., Steedman, T., Payne, J., Shaw, M., et al. (2011) Radiofrequency ablation for persistent atrial fibrillation in patients with advanced heart failure and severe left ventricular systolic dysfunction: A randomised controlled trial. Heart, 97, 740-747. doi:10.1136/hrt.2010.207340

[67] Wilton, S.B., Fundytus, A., Ghali, W.A., Veenhuyzen, G.D., Quinn, F.R., Mitchell, L.B., Hill, M.D., Faris, P. and Exner, D.V. (2010) Meta-analysis of the effectiveness and safety of catheter ablation of atrial fibrillation in patients with versus without left ventricular systolic dysfunction. American Journal of Cardiology, 106, 12841291. doi:10.1016/j.amjcard.2010.06.053

[68] Dagres, N., Varounis, C., Gaspar, T., Piorkowski, C., Eitel, C., Iliodromitis, E.K., Lekakis, J.P., Flevari, P., Simeonidou, E., Rallidis, L.S., Tsougos, E., Hindricks, G., Sommer, P. and Anastasiou-Nana, M. (2011) Catheter ablation for atrial fibrillation in patients with left ventricular systolic dysfunction. A systematic review and meta-analysis. Journal of Cardiac Failure, 17, 964-970. doi:10.1016/j.cardfail.2011.07.009

[69] St. Luke's-Roosevelt Hospital Center (2011) Pulmonary vein isolation for rhythm control in patients with atrial fibrillation and left ventricular dysfunction: A pilot study. ClinicalTrials.gov identifier: NCT01082601.

[70] Barts \& The London NHS Trust (2010) Catheter ablation versus medical treatment of AF in heart failure (CAMTAF). ClinicalTrials.gov identifier: NCT01411371

[71] Royal Brompton \& Harefield NHS Foundation Trust (2012) Catheter ablation versus medical rate control for atrial fibrillation in patients with heart failure (ARC-HF). ClinicalTrials.gov identifier: NCT00878384

[72] St. Jude Medical (2012) Atrial fibrillation management in congestive heart failure with ablation (AMICA). ClinicalTrials.gov identifier: NCT00652522

[73] Marrouche, N.F., Brachmann, J. and CASTLE-AF Steering Committee (2009) Catheter ablation versus standard conventional treatment in patients with left ventricular dysfunction and atrial fibrillation (CASTLE-AF) - Study design. Pacing and Clinical Electrophysiology, 32, 987994. doi:10.1111/j.1540-8159.2009.02428.x

[74] University of Ottawa Heart Institute (2012) Rate versus catheter ablation rhythm control in patients with heart failure and high burden atrial fibrillation (RAFT-AF). ClinicalTrials.gov identifier: NCT01420393. 